\title{
Sistemas Regionais de Inovação no Setor Farmacêutico Brasileiro: Estudo Comparativo
}

\author{
Julia Paranhos ${ }^{1}$ \\ Caio França ${ }^{2}$ \\ Eduardo Mercadante ${ }^{3}$
}

\begin{abstract}
RESUMO
O presente estudo visa caracterizar a configuração regional do setor farmacêutico brasileiro, tendo por base as abordagens de sistemas regionais e setoriais de inovação. Para tanto, foram analisados dados secundários do setor produtivo e de ciência e tecnologia de cinco estados da federação - Rio de Janeiro, São Paulo, Goiás, Minas Gerais e Pernambuco. Os resultados indicam queda de participação do setor farmacêutico na atividade econômica de Rio de Janeiro e São Paulo, enquanto Goiás destacou-se pelo crescimento. Contudo, São Paulo e Rio permanecem em posição de destaque quanto à capacitação científica, abrigando maior número de instituições de pesquisa e cursos superiores e de pós-graduação voltados ao setor. As políticas estaduais refletem estratégias heterogêneas, mas que apresentam como ponto comum a concessão de diferentes modalidades de incentivos fiscais. O estudo apresentado identifica aspectos político-econômicos relevantes à elaboração de políticas públicas para o fortalecimento do setor farmacêutico, especialmente, no Rio de Janeiro.
\end{abstract}

PALAVRA-CHAVE: Setor farmacêutico; Sistemas regionais de inovação; Sistemas setoriais de inovação; Políticas públicas.

\section{ABSTRACT}

This study aims to characterize the regional setting of the Brazilian pharmaceutical sector, based on the regional and sectoral innovation systems approaches. To this end, secondary data from the productive sector and science and technology of five states of the federation- Rio de Janeiro, São Paulo, Goiás, Minas Gerais and Pernambuco were analyzed. The results show a drop in the participation of the pharmaceutical sector in the economic activity of Rio de Janeiro and São Paulo, while Goiás has been facing growth. Nevertheless, São Paulo and Rio de Janeiro remain in a prominent position regarding scientific capacities, housing a large body of research institutions and higher education and postgraduate courses relevant to the sector. State policies reflect heterogeneous strategies that have tax incentives as common point. The present study identifies political and economic aspects relevant to the development of public policies to strengthen the pharmaceutical industry, especially in Rio de Janeiro.

KEYWORDS: Pharmaceutical sector; Regional innovation systems; Sectoral innovation systems; Public policy.

1 Professora Associada da Universidade Federal do Rio de Janeiro e coordenadora do Grupo de Economia da Inovação do Instituto de Economia da UFRJ. Diretora Adjunta de Graduação do IE/UFRJ entre agosto de 2015 e julho de 2017. Graduada em Ciências Econômicas pela UFRJ (2004), mestre em Economia Industrial pela Universidade Federal de Santa Catarina (2006) e doutora em Economia da Indústria e da Tecnologia pela UFRJ (2010) com período de doutorado sanduíche no Science and Technology Policy Research - SPRU (2009). Membro da Associação Brasileira de Economia Industrial e Inovação (ABEIN). Tem experiência na área de Economia, com ênfase em Inovação, atuando principalmente nos temas: gestão da inovação, política industrial e de inovação, relação universidade-empresa e propriedade industrial, em especial no setor farmacêutico.

2 Graduado em Biomedicina pela UFRJ, mestre em Biologia Celular e Molecular, com ênfase em farmacologia, pelo IOC-Fiocruz, e doutor em Políticas Públicas, Estratégias e Desenvolvimento, com ênfase em Inovação e Propriedade Intelectual, pelo Instituto de Economia da UFRJ. Atualmente, está exclusivamente dedicado à Propriedade Industrial, atuando como especialista de patentes na área de Ciências da Vida. Em experiência pregressa, coordenou, por 4 anos, as estratégias de patenteamento envolvendo 3 tecnologias em uma start-up biofarmacêutica, onde também conduziu o desenvolvimento pré-clínico de um novo candidato a fármaco para tratamento de diabetes.

3 Aluno de Doutorado em Desenvolvimento Internacional na London School of Economics and Political Sciences (LSE). Bacharel em Ciências Econômicas e Mestre em Políticas Públicas, Estratégias e Desenvolvimento pela Universidade Federal do Rio de Janeiro (UFRJ). Pesquisador convidado no Grupo de Economia da Inovação (GEI/IE/ UFRJ). Temas de pesquisa principais são políticas de inovação e propriedade intelectual e estratégias de empresas no setor farmacêutico de países em desenvolvimento. 


\section{1- Introdução}

Segundo Ferraz, De Paula e Kupfer (2013, p. 313), a política industrial tem o objetivo de promover a "atividade produtiva, na direção de estágios de desenvolvimento superiores aos pré-existentes em um determinado espaço nacional". Pela ótica neo-schumpeteriana, as inovações são o motor do desenvolvimento e, por isso, devem ser o foco de uma política industrial ativa. Nesse sentido, abre-se espaço para a intervenção pública orientada para estimular as empresas para a busca, desenvolvimento e geração de inovação e para a criação de um ambiente propício a esses processos. Diversos instrumentos são utilizados pelos governos para esse fim, como subvenção econômica a projetos de inovação, incentivos fiscais a atividades de pesquisa e desenvolvimento (P\&D), e uso do poder de compra do governo. Pressupõe-se, nessa ótica, que a geração de inovação é um processo endógeno e sistêmico que requer esforços das empresas para sua geração, assim como a interação das empresas com os demais atores do sistema fornecedores, clientes, universidades, centros de pesquisa, instituições financeiras e o governo (FREEMAN, 1995; LUNDVALL et al., 2002).

No Brasil, os instrumentos de estímulo e apoio à inovação passam a ser utilizados pelo governo, principalmente, a partir do início dos anos 2000, com a retomada da política industrial, em 2003, com a Política Industrial, Tecnológica e de Comércio Exterior (Pitce) e a promulgação de leis que permitissem o uso destes instrumentos, a Lei 10.973/2004 - Lei da Inovação - que autoriza a subvenção econômica ${ }^{4}$, e a Lei 11.196/2005 - Lei do Bem - que cria o automatismo ao uso de incentivos fiscais para projetos de P\&D. As ações em âmbito nacional geram efeitos no nível estadual. Nos períodos subsequentes, foram estabelecidas Leis de Inovação estaduais, incentivos fiscais e programas de financiamento e subvenção econômica nas Fundações de Amparo à Pesquisa (FAPs) nos estados.

De acordo com Ohmae (1995 apud COOKE, 1998 p. 16, tradução nossa), as regiões "representam comunidades de interesse autênticas, definem fluxos significativos de atividades econômicas e são beneficiadas por verdadeiras sinergias e conexões entre atores econômicos". Faz sentido, então, um recorte regional para um entendimento mais profundo do processo de inovação, já que, ainda que dentro do mesmo país, diferentes regiões podem apresentar diferentes configurações e características dependendo, principalmente, das suas trajetórias tecnológicas e suas bases de conhecimento (ASHEIM; GERTLER, 2005). Conforme afirmam Cooke, Uranga e Etxebarria (1997), essas diferenças regionais podem refletir também nas diferenças dos aspectos organizacionais das empresas, do setor público e das instituições de P\&D. Nesse sentido, a abordagem do sistema regional de inovação (SRI) ajuda a identificar os principais atores envolvidos no processo de aprendizado para gerar inovações, bem como os obstáculos que devem ser resolvidos pelas instituições locais. A partir dessa análise, pode-se então estabelecer políticas públicas no apoio, estímulo e financiamento às atividades inovativas e interação entre os atores de uma região específica, como defendido por Cooke (1998).

Breschi e Malerba (1997), por outro lado, chamam atenção para a importância das diferenças setoriais no processo de inovação. Isso porque, conforme afirma Malerba (2005), as inovações terão características, fontes, atores, processo e organização de atividades inovativas diferentes entre os diversos setores. Nesse sentido, a abordagem dos sistemas setoriais de inovação (SSI) permite levar em consideração diferenças no conhecimento e nas tecnologias dos diferentes setores, nos atores, relacionamentos e redes relevantes, e ainda nas diferenças institucionais presentes em cada setor. Uma abordagem setorial possibilita ainda a análise e o estabelecimento de políticas, para geração e difusão de inovação, específicas ao setor, ainda que não exclua a necessidade de políticas complementares e de suporte mais abrangentes. No entanto, deve considerar também as diferenças de dimensões geográficas do sistema setorial - local, nacional, regional e global.

4 Recursos não reembolsáveis destinados a promoção de atividades inovativas nas empresas. 
Segundo Lundvall et al. (2002), as novas dimensões de análise são complementares à análise da dimensão nacional, pois buscam ampliar a capacidade de entendimento sobre as complexas interações presentes nos sistemas de inovação. Sendo assim, neste artigo, as dimensões regionais e setoriais serão utilizadas em conjunto para o maior entendimento da configuração regional do setor farmacêutico no Brasil. A combinação dessas duas abordagens implica no recorte regional (cinco estados da federação) e setorial (setor farmacêutico) para uma análise de dados de atores e instituições relevantes para o desenvolvimento de inovações a partir de uma visão sistêmica.

Desde 2003, o setor farmacêutico está no foco das políticas industriais brasileiras e de seus programas de apoio à produção local e inovação. Os resultados de tais esforços são perceptíveis ao analisarem-se os dados em âmbito nacional, mas há fortes diferenças na configuração e nas tendências de desenvolvimento e crescimento do setor em âmbito regional. Em particular, temse o caso do estado do Rio de Janeiro (RJ) que configura como a segunda maior concentração de empresas farmacêuticas e apresenta um significativo número de instituições científicas e tecnológicas, possuindo, assim, atores relevantes para o desenvolvimento inovativo do setor regionalmente. Não obstante, passa por um período de perda de participação no cenário nacional. Muitos estudos analisam o setor farmacêutico nacional e os efeitos das políticas públicas no seu desenvolvimento (SELAN; KANNEBLEY JUNIOR; PORTO, 2007; PALMEIRA FILHO, 2013; RADAELLI, 2012), mas poucos com o enfoque regional/local (GOMES, 2014).

Portanto, o objetivo neste artigo é apresentar a configuração regional do setor farmacêutico do RJ em comparação com o estado de São Paulo (SP), estado de Goiás (GO), estado de Minas Gerais (MG) e estado de Pernambuco (PE), em termos de capacidade científica, tecnológica e produtiva, além das diferenças em termos de políticas e ações dos governos estaduais. Busca-se, por fim, especular sobre os efeitos das políticas estaduais para a promoção e desenvolvimento do setor farmacêutico brasileiro no âmbito regional e os desafios que estão postos para o governo do RJ nesse sentido. Esses estados foram escolhidos por terem destaque no setor farmacêutico nacional, no caso de São Paulo, e por apresentarem crescimento na participação do setor nacional, no caso de Goiás com genéricos, Minas Gerais com biotecnologia e Pernambuco com novos investimentos por empresa multinacional.

O artigo está dividido em três seções, além desta Introdução e da seção de Discussão e Conclusão. Na primeira seção, são apresentados a metodologia, os dados utilizados e suas fontes. Na segunda seção, são analisados os dados secundários referentes à ciência e tecnologia e à capacidade produtiva do RJ e dos demais quatro estados analisados. Na terceira seção, são apresentados programas, políticas e leis dos governos estaduais para desenvolvimento do setor farmacêutico local.

\section{2- Metodologia}

A metodologia de pesquisa foi a de levantamento bibliográfico e de dados secundários dos estados analisados, a saber, RJ, SP, GO, MG e PE. Foram levantados dados secundários do setor produtivo, do setor de ciência e tecnologia, e as principais políticas estaduais de apoio ao desenvolvimento do sistema farmacêutico de inovação.

O levantamento bibliográfico introduzido na sessão anterior norteou a interpretação dos dados compilados. A literatura pertinente fundamenta a abordagem dos sistemas de inovação nas suas dimensões regional (COOKE, 1998; COOKE; URANGA; ETXEBARRIA, 1997) e setorial (BRESCHI; MALERBA, 1997; MALERBA, 2005), bem como estudos sobre o desenvolvimento do setor farmacêutico nacional e as políticas públicas e ações governamentais para seu desenvolvimento (SELAN; KANNEBLEY JUNIOR; PORTO, 2007; PALMEIRA FILHO, 2013; RADAELLI, 2012; HASENCLEVER, 2012; PARANHOS, 2012; GOMES, 2014). 
Os dados secundários foram coletados na Relação Anual de Informações Sociais do Ministério do Trabalho e Emprego (RAIS/MTE) e nas pesquisas de produção física e inovação do Instituto Brasileiro de Geografia e Estatística (PIM-PF/IBGE), para a caracterização do setor produtivo; e nas bases do Conselho Nacional de Desenvolvimento Científico e Tecnológico, da Coordenação de Aperfeiçoamento de Pessoal de Nível Superior (Capes) e do Ministério da Educação (MEC), para caracterização do setor de ciência e tecnologia. Para os cursos de graduação, foram investigados apenas os de áreas diretamente ligadas com o setor farmacêutico. Para os grupos de pesquisa e os cursos de pós-graduação, o escopo de análise foi ampliado, visto que a especialização permite que determinadas áreas afetem indiretamente o setor farmacêutico por mais que, no âmbito da graduação, não tenham externalidades significativas.

O levantamento das ações governamentais foi realizado através de informações disponíveis nos sítios eletrônicos das secretarias estaduais de Fazenda, de Ciência e Tecnologia e de Desenvolvimento Econômico. Foram levantadas as políticas públicas relacionadas ao desenvolvimento do setor farmacêutico nos estados, e as principais fontes de financiamento em nível nacional e estadual. Buscou-se identificar a legislação estadual pertinente ao tema e as políticas estaduais de apoio à indústria, ciência e tecnologia com implicações, diretas ou indiretas, sobre o setor farmacêutico, as agências de financiamento e fomento com atuação local, além de outros dados relevantes.

\section{3- A Configuração Produtiva e de Ciência e Tecnologia do Setor Farmacêutico em Âmbito Regional}

Nesta seção, são apresentados dados secundários para caracterização do sistema farmacêutico de inovação fluminense, especificamente seu setor produtivo e seu setor de ciência e tecnologia. Essas informações são comparadas com as informações de outros importantes estados do país para o setor farmacêutico: SP, GO, MG e PE, conforme explicado na Metodologia.

\section{1- Dados do Setor Produtivo}

Em termos produtivos, como também apresentado em Hasenclever (2012), o setor farmacêutico apresenta forte queda nos últimos 18 anos, conforme pode-se perceber na análise dos dados da RAIS/MTE e da PIM-PF/IBGE apresentados a seguir. Pelos dados de número de estabelecimentos apresentados no Gráfico 1, percebe-se uma redução significativa na participação do número de estabelecimentos do setor farmacêutico no RJ no total do país. Em 1995, localizavam-se no estado cerca de 19,8\% dos estabelecimentos do setor farmacêutico do país, compreendendo os estabelecimentos produtores de farmoquímicos e de medicamentos para uso humano. No entanto, no final do período analisado, 2013, esse percentual chega a atingir apenas $12,8 \%$. Essa queda de 7 pontos percentuais (p.p.) ganha maior importância quando comparada à queda de 3 p.p. de SP e o crescimento dos outros estados no Brasil. Importante ressaltar que essas tendências ocorrem também em números absolutos, com uma redução no número de estabelecimentos farmacêuticos no RJ de 53,6\% e em SP de 33,7\% nesses 18 anos, passando de 181 para 84 e de 356 a 236 estabelecimentos, respectivamente. É interessante, também, perceber a grande evolução de GO. Em 1995, tinha 2,5\% e era o quinto entre os estados analisados. Já, em 2013, passou a ter 10,2\% (67 estabelecimentos), superando MG como a terceira maior parcela dos estabelecimentos nacionais. $\mathrm{PE}$, por mais que tenha perdido $35 \%$ de seus estabelecimentos - restando apenas 26 em 2013 -, praticamente manteve a sua porcentagem, já que o Brasil inteiro teve uma redução de $28,6 \%$ em valores absolutos, partindo de 916 e terminando com 654 estabelecimentos. 
Gráfico 1: Porcentagem de estabelecimentos do setor farmacêutico

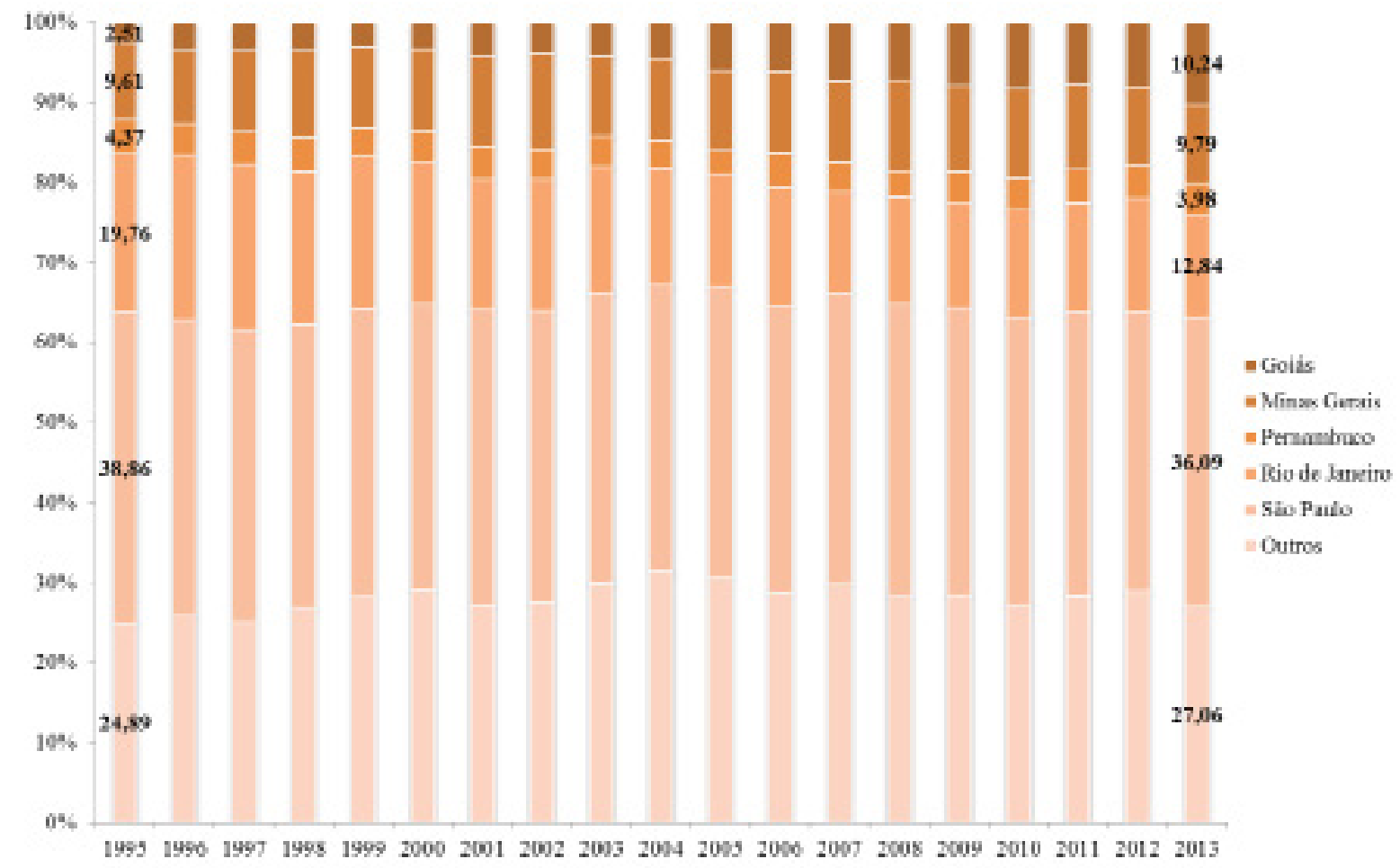

Fonte: Elaborado por GEI/IE/UFRJ, com base em RAIS/MTE (2015).

O número de trabalhadores formais empregados nas empresas farmacêuticas no RJ apresenta uma queda ainda mais expressiva do que aquela do número de estabelecimentos, como pode ser observado no Gráfico 2. Em 1995, 21,9\% dos trabalhadores estavam empregados no setor farmacêutico do RJ, mas em 2013 essa porcentagem caiu para 9,5\%, causando uma queda importante no número de empregos formais no setor de 12 p.p.. SP apresentou uma redução, porém muito inferior (6 p.p.) e PE, ainda menor (1 p.p.) - que, no entanto, significou que sua participação caiu pela metade. Outros dois movimentos significativos foram os crescimentos das parcelas de GO e MG. O primeiro saltou de 3,1\% para 12,4\%; o segundo, de 3,7\% para 7,9\%. O resultado dessas alterações foi, mais uma vez, muito positivo para GO; ele passou de quarto para segundo estado que mais emprega no setor farmacêutico, superando o RJ e ficando atrás apenas de SP. Isso demonstra a descentralização do emprego no setor farmacêutico, com o forte crescimento de MG e GO levando à redução da participação relativa de SP, mesmo com crescimento em termos absolutos.

Quando são analisados os números absolutos de emprego no setor farmacêutico, fica clara a profunda mudança na composição. RJ perdeu $31 \%$ e PE, 15,8\%; por outro lado, SP cresceu $43,2 \%, M G, 238,1 \%$ e GO, impressionantes $540 \%$. Isto é, combinando as duas tendências, é possível afirmar que SP perdeu participação, mas não teve queda no número absoluto de empregados, enquanto o RJ perdeu em participação relativa e em número absoluto de empregados no setor farmacêutico. Por outro lado, MG e, principalmente, GO vieram na contramão, aumentando em termos relativos e absolutos o número de estabelecimentos e empregados no setor farmacêutico. 


\section{Gráfico 2: Porcentagem de trabalhadores empregados em estabelecimentos do setor farmacêutico}

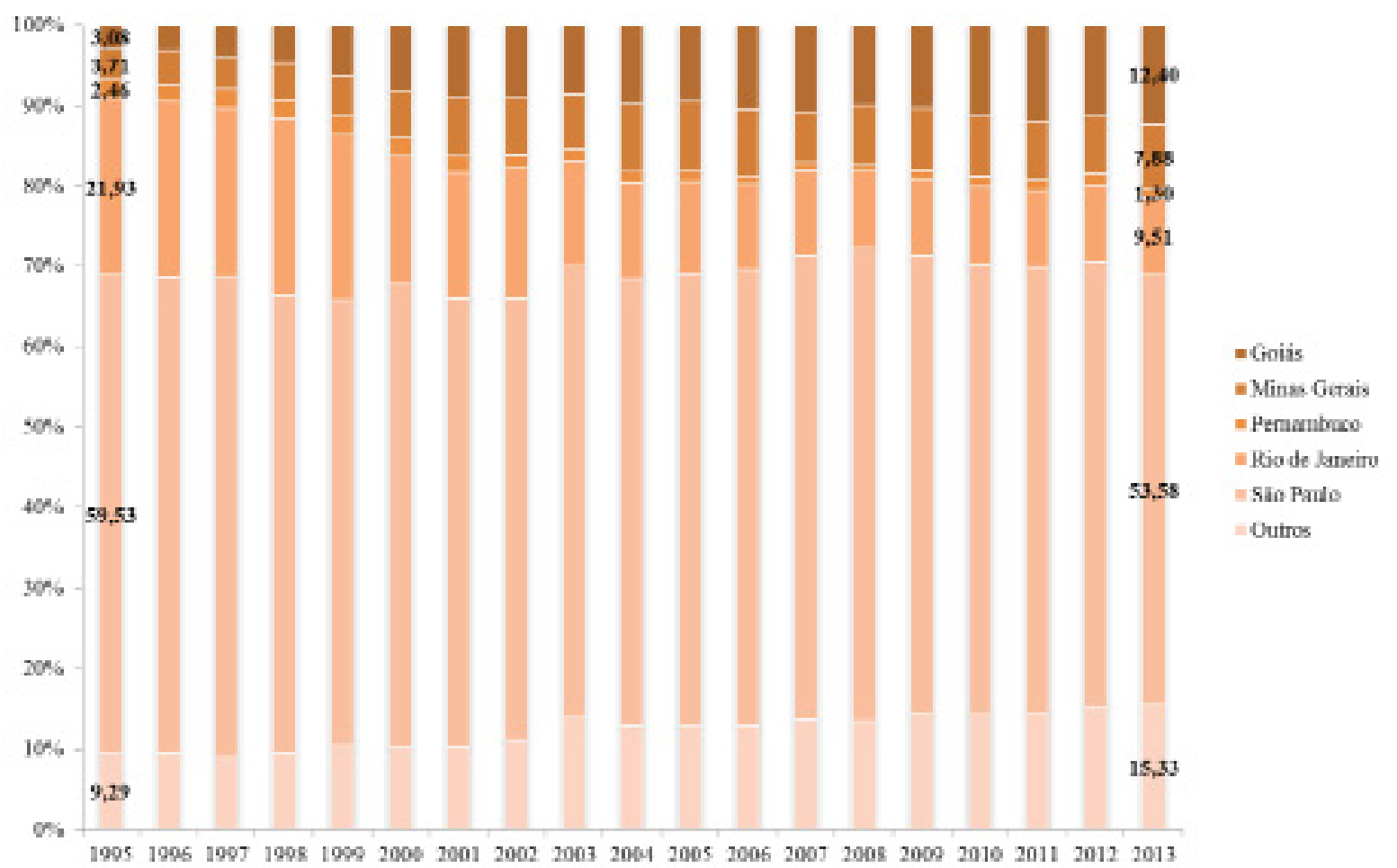

Fonte: Elaborado por GEI/IE/UFRJ, com base em RAIS/MTE (2015).

Vale observar ainda que a queda no número de trabalhadores foi acompanhada não somente pela redução no número de estabelecimentos, mas também pela queda significativa na produção física do setor farmacêutico no RJ, de acordo com os dados da PIM-PF/IBGE. O Gráfico 3 abaixo apresenta os índices de produção física do setor farmacêutico e da indústria de transformação do RJ e do Brasil no período de 1996 a 2012, com base no ano de 1996. Os dados também mostram a importância de SP para a produção física do setor farmacêutico no Brasil. Os mesmos dados não estão disponíveis para os demais estados, mas percebe-se a importância de SP e a forte queda do RJ.

Gráfico 3: Produção física da Indústria de transformação e farmacêutica no Brasil, RJ e SP (1996/2012)

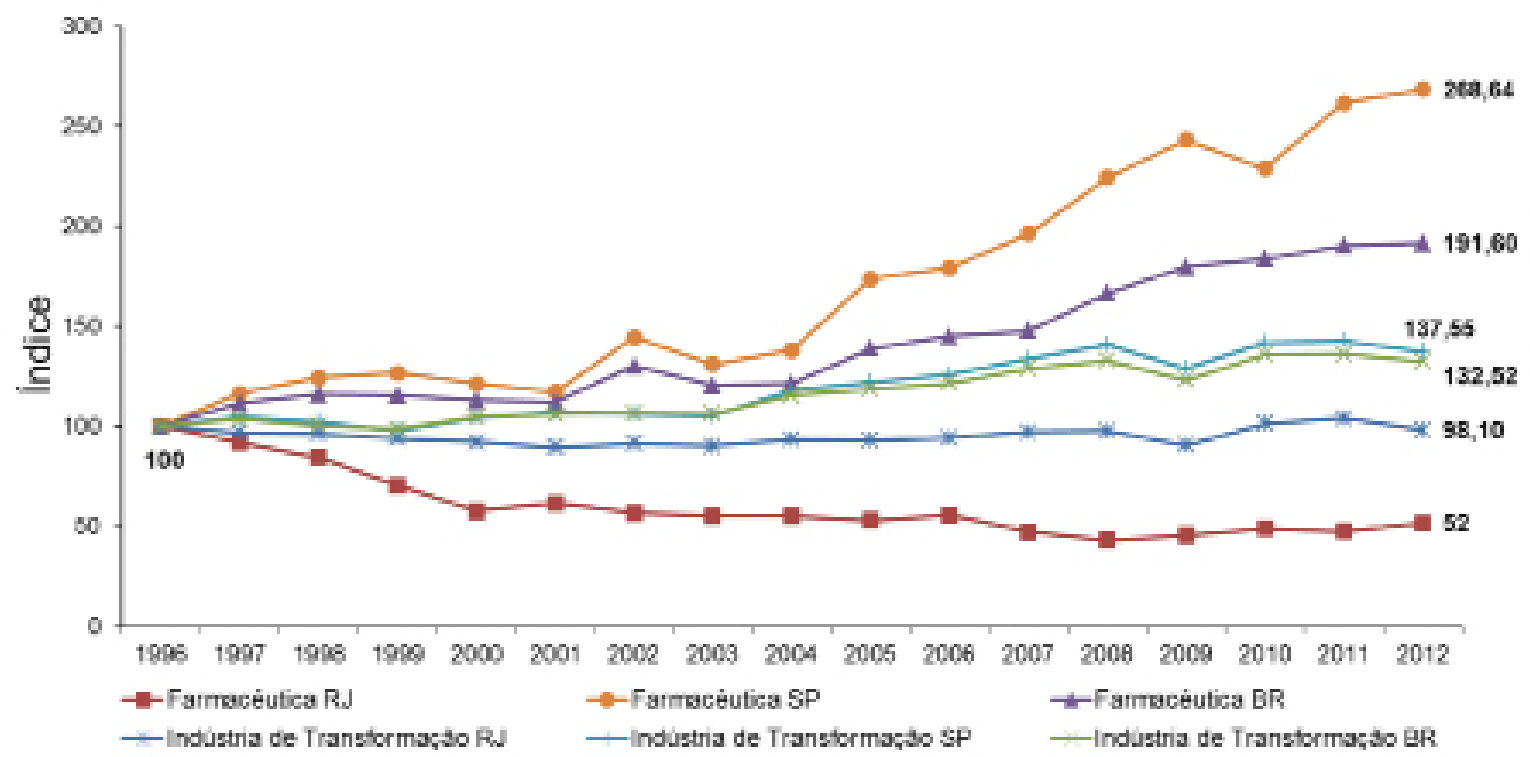

Fonte: Elaborado por GEI/IE/UFRJ com base em PIM-PF/IBGE (2013). 
O curioso de se constatar é que a relação entre a produção física das indústrias farmacêutica e de transformação no RJ, durante o período em questão, é inversa à mesma relação no âmbito nacional. No RJ, a indústria farmacêutica apresenta queda na produção física, chegando a $57 \%$ negativos em 2008, o índice mais baixo no período analisado, e 51,1\% negativos em 2010. Esses valores são bastante inferiores aos da indústria de transformação fluminense, que não apresenta uma evolução muito positiva, mas mantém-se estável.

No mesmo período, o crescimento na produção física da indústria farmacêutica no Brasil é maior que o da produção física da indústria de transformação no país durante todo o período analisado. A indústria de transformação, a um nível nacional, apresenta um aumento de quase $33 \% \mathrm{em}$ 2012, enquanto a produção física da indústria farmacêutica apresenta taxas ainda superiores, alcançando $91,6 \%$ de crescimento em 2012, enquanto comparada com 1996. Isso mostra uma grande importância da indústria farmacêutica no país enquanto setor dinâmico. A diferença é ainda maior quando os dados de SP são analisados. Apesar da produção física da indústria de transformação no estado ter crescido $37,5 \%$, a produção física da indústria farmacêutica aumentou em quase $267 \%$, uma diferença enorme quando comparada com o RJ.

É possível notar um encolhimento da indústria farmacêutica no RJ, que é negativo para seu desenvolvimento. Em particular, esses resultados não são bons para o desenvolvimento de inovações, porque, normalmente, quando o desempenho de uma empresa não vai bem, a primeira ação é cortar investimentos em P\&D.

\section{2- Dados de ciência e tecnologia}

O RJ possui significativa especialização nas áreas do conhecimento relacionadas ao setor farmacêutico, demonstrando uma forte capacidade científica e de formação de recursos humanos, como apresentado em Hasenclever (2012). São ao todo 43 instituições de científicas e tecnológicas $(I C T s)^{5}$ públicas e privadas, das quais dez são universidades estaduais (UERJ, UENF e UEZO) ${ }^{6}$ e sete são universidades federais (IFF, IFRJ, UFF, UFRJ, UFRRJ, IME, Unirio)7. Existe um total de 147 cursos de graduação nas grandes áreas do conhecimento relacionadas ao setor farmacêutico; os mais frequentes são Ciências Biológicas (57\%), Farmácia (21\%) e Química (21\%). Britto et al. (2011) também considera esse cenário muito significativo para o desenvolvimento do estado, devido à importância que as universidades e institutos de pesquisa têm para o desenvolvimento das inovações no setor farmacêutico, conforme Klevorick et al. (1995), Mansfield (1998), Mckelvey e Orsenigo (2001).

Comparando o RJ, em termos de cursos de graduação, com os demais estados em análise, percebese que, em valores totais, SP e MG destacam-se. SP apresenta, em valores arredondados, o dobro dos cursos do segundo lugar, MG, e o triplo do terceiro, RJ. GO aparece em quarto, com quase o dobro de cursos de PE, que apresenta menos de 60 cursos em áreas ligadas ao setor farmacêutico. No entanto, apesar dessa grande diferença em quantidade, a composição é muito parecida. Todos possuem uma concentração de quase metade dos cursos nas áreas de Ciências Biológicas, enquanto Química e Farmácia, nessa ordem, aparecem próximos com mais ou menos um quarto cada. Uma última análise ainda significativa é a percepção do desenvolvimento dos cursos de Biotecnologia no ESP, com 11 cursos, enquanto só RJ e GO possuem um curso, respectivamente, nessa área.

$5 \quad$ Inclui universidades e institutos de pesquisa.

$6 \quad$ Universidade do Estado do Rio de Janeiro, Universidade Estadual do Norte Fluminense, e Centro Universitário Estadual da Zona Oeste.

$7 \quad$ Instituto Federal Fluminense, Instituto Federal do Rio de Janeiro, Instituto Militar de Engenharia, Universidade Federal Fluminense, Universidade Federal do Rio de Janeiro, Universidade Federal Rural do Rio de Janeiro, e Universidade Federal do Estado do Rio de Janeiro.

8

A outra é Biotecnologia, com apenas $1 \%$. 
Tabela 1: Cursos de graduação no setor farmacêutico, 2015

\begin{tabular}{|c|c|c|c|c|c|c|}
\hline Áreas de Conhecimento & Goiás & Minas Gerais & Pernambuco & Rio de Janeiro & São Paulo & TOTAL \\
\hline Biotecnologia (1) & 1 & - & - & 1 & 11 & $\mathbf{1 3}$ \\
\hline Ciências Biológicas (2) & 50 & 110 & 25 & 84 & 228 & $\mathbf{4 9 7}$ \\
\hline Farmácia (3) & 27 & 70 & 14 & 31 & 122 & $\mathbf{2 6 4}$ \\
\hline Química (4) & 28 & 91 & 20 & 31 & 170 & $\mathbf{3 4 0}$ \\
\hline TOTAL & $\mathbf{1 0 6}$ & $\mathbf{2 7 1}$ & $\mathbf{5 9}$ & $\mathbf{1 4 7}$ & $\mathbf{5 3 1}$ & $\mathbf{1 1 1 4}$ \\
\hline
\end{tabular}

Fonte: Elaborado pelo GEI/IE/UFRJ com base em MEC (2015).

Nota: (1) Biotecnologia inclui: Engenharia de Bioprocessos e Biotecnologia; e Engenharia de Biotecnologia.

(2) Ciências Biológicas inclui: Biofísica; Biologia Marinha; Biologia Vegetal; Genética; Ecologia;

Ênfase em Biologia Ambiental; Ênfase em Biologia Evolutiva; Ênfase em Biologia Molecular e Tecnológica; Matemática Aplicada com Habilitação em Ciências Biológicas; Matemática Aplicada e Computacional com Habilitação em Ciências Biológicas; Microbiologia e Imunologia; Modalidade

Médica; e Zoologia.

(3) Farmácia inclui: Farmácia e Bioquímica.

(4) Química inclui: Atribuições em Biotecnologia; Atribuições Tecnológicas; Ciências Exatas com Habilitação em Química; Ênfase em Bioquímica e Biologia Molecular; Engenharia Química; Habilitação em Química Forense; Habilitação em Química Tecnológica, Biotecnologia e Agroindústria; Opção Tecnológica com Ênfase em Alimentos; Opção Fundamental; Opção Tecnológica com Ênfase em Gestão de Qualidade; Opção Tecnológica - Ênfase Ambiental; Opção

Tecnológica - Ênfase em Materiais; Programa Especial de Formação Pedagógica de Docentes Química; Química Ambiental; Química Ambiental Tecnológica; Química/Física; Química Industrial; e Química Tecnológica.

Também em termos de pós-graduação, a capacitação do RJ em áreas relacionadas ao setor farmacêutico é forte (HASENCLEVER, 2012). Existem 21 ICTs, sendo três universidades estaduais (UENF, UERJ, UEZO), quatro universidades federais (UFF, UFRJ, UFRRJ, Unirio), dez institutos federais de pesquisa (CEFET/RJ, Fiocruz, LNCC, IME, IMPA, INC, INCA, INMETRO, INPI, INTO) ${ }^{9}$ e quatro universidades privadas (PUC-Rio, UCAM, UNESA e UniFOA) ${ }^{10}$. Nessas ICTs, há 94 mestrados, 27 mestrados profissionais e 79 doutorados nas áreas do conhecimento relacionadas ao setor farmacêutico, como pode ser visto na Tabela 2. Percebese uma concentração dos cursos nas três áreas de Ciências Biológicas, totalizando $20 \%$ dos mestrados, $15 \%$ dos mestrados profissionais e $20 \%$ dos doutorados; nas Engenharias, com $21 \%$ dos mestrados, $15 \%$ dos mestrados profissionais e $15 \%$ dos doutorados; e nas áreas de Medicina, com $21 \%$ dos mestrados, $22 \%$ dos mestrados profissionais e $28 \%$ dos doutorados.

Ressalta-se a mudança de posicionamento entre MG e RJ, e PE e GO, quando analisados os cursos de graduação e pós-graduação. MG apresenta mais cursos de graduação que o RJ, mas na pós-graduação essa situação é invertida. Da mesma maneira, GO apresenta o maior número de cursos de graduação que $\mathrm{PE}$, mas o posicionamento é invertido quando se trata dos cursos de pós. Por outro lado, SP é líder nos dois níveis de cursos, quando somados os totais.

9 Centro Federal de Educação Tecnológica Celso Suckow da Fonseca; Laboratório Nacional de Computação Científica; Instituto Militar de Engenharia; Instituto Nacional de Matemática Pura e Aplicada; Instituto Nacional de Cardiologia; Instituto Nacional de Câncer; Instituto Nacional de Metrologia, Qualidade e Tecnologia; Instituto Nacional da Propriedade Industrial; e Instituto Nacional de Traumatologia e Ortopedia.

10 Pontifícia Universidade Católica do Rio de Janeiro; Universidade Candido Mendes; Universidade Estácio de Sá; e Centro Universitário de Volta Redonda. 
Tabela 2: Cursos de pós-graduação no sistema de inovação farmacêutico no RJ, 2013

\begin{tabular}{|c|c|c|c|c|c|}
\hline \multirow{2}{*}{\multicolumn{3}{|c|}{ Características }} & \multicolumn{3}{|c|}{ Número de cursos de pós-graduação } \\
\hline & & & \multirow{2}{*}{$\begin{array}{c}\text { Mestrado } \\
3\end{array}$} & \multirow{2}{*}{$\begin{array}{c}\begin{array}{c}\text { Mestrado } \\
\text { Profissional }\end{array} \\
-\end{array}$} & \multirow{2}{*}{ 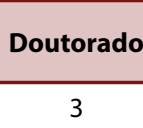 } \\
\hline \multirow{16}{*}{\multicolumn{2}{|c|}{ Área de Conhecimento }} & Biotecnologia & & & \\
\hline & & Ciência Biológicas I & 5 & - & 4 \\
\hline & & Ciência Biológicas II & 8 & 4 & 7 \\
\hline & & Ciência Biológicas III & 6 & - & 5 \\
\hline & & Engenharia II & 11 & 1 & 8 \\
\hline & & Engenharia III & 8 & 3 & 3 \\
\hline & & Engenharia IV & 1 & - & 1 \\
\hline & & Farmácia & 2 & 3 & 1 \\
\hline & & Interdisciplinar & 9 & 1 & 7 \\
\hline & & Matemática & 5 & - & 5 \\
\hline & & Materiais & - & 2 & - \\
\hline & & Medicina I & 9 & 1 & 9 \\
\hline & & Medicina II & 9 & 4 & 9 \\
\hline & & Medicina III & 2 & 1 & 2 \\
\hline & & Química & 7 & - & 7 \\
\hline & & Saúde Coletiva & 9 & 7 & 8 \\
\hline \multicolumn{3}{|c|}{ TOTAL } & 94 & 27 & 79 \\
\hline \multirow{4}{*}{$\begin{array}{l}\text { Status } \\
\text { Jurídico }\end{array}$} & \multirow{2}{*}{ Do Curso } & Pública & 87 & 24 & 72 \\
\hline & & Privada & 7 & 3 & 5 \\
\hline & \multirow{2}{*}{ Da Instituição } & Pública & 12 & 10 & 12 \\
\hline & & Privada & 3 & 3 & 2 \\
\hline
\end{tabular}

Fonte: Elaborado por GEI/IE/UFRJ, com base em Capes (2015).

Tabela 3: Participação (\%) dos estados analisados nos cursos pós-graduação relacionados ao setor farmacêutico, 2013

\begin{tabular}{|c|c|c|c|}
\hline Estado & Mestrado & Mestrado Profissional & Doutorado \\
\hline Goiás & 3 & 2 & 3 \\
\hline Minas Gerais & 16 & 16 & 14 \\
\hline Pernambuco & 7 & 8 & 5 \\
\hline Rio de Janeiro & 23 & 42 & 55 \\
\hline São Paulo & 51 & 33 & 23 \\
\hline
\end{tabular}

Fonte: Elaborado por GEI/IE/UFRJ, com base em Capes (2015).

No que diz respeito à pesquisa, há alguns dados significativos sobre grupos reconhecidos pelo CNPq - com informações atualizadas em 2010. Dos 4.043 grupos ligados ao setor farmacêutico - que estão representados na Tabela 4 -, foram auferidas as participações de cada um dos cinco estados relevantes a essa pesquisa: SP (47\%), RJ (27\%), MG (18\%), PE (6\%) e GO (2\%). Portanto, mais uma vez SP foi o grande centro, totalizando quase metade dos grupos investigados, com o RJ em segundo lugar, com praticamente um quarto do total, ambos com mais de mil grupos. Novamente nas últimas posições, MG, PE e GO (em ordem decrescente de participação) totalizam apenas um quarto dos grupos de pesquisa em áreas ligadas ao setor farmacêutico, em 2010. 
Tabela 4: Número de grupos de pesquisa ligados ao setor farmacêutico, 2010

\begin{tabular}{|c|c|}
\hline Estado & Número de Grupos \\
\hline Goiás & 91 \\
\hline Minas Gerais & 731 \\
\hline Pernambuco & 243 \\
\hline Rio de Janeiro & 1080 \\
\hline São Paulo & 1898 \\
\hline
\end{tabular}

Fonte: Elaborado por GEI/IE/UFRJ, com base em CNPq, 2015.

Nota: Foram seleciadas as áreas de conhecimento: Biofísica; Biologia Geral; Bioquímica;

Engenharia Biomédica; Engenharia de Materiais e Metalúrgica; Engenharia de Produção;

Engenharia Química; Farmácia; Farmacologia; Fisiologia; Genética; Imunologia; Matemática; Medicina; Microbiologia; Morfologia; Parasitologia; Probabilidade e Estatística; Química; e

Saúde Coletiva.

Resumindo, os dados mostram que há um número significativo de atores e capacidades locais no RJ em ciência e tecnologia, em geral, e no setor farmacêutico, em particular, em termos absolutos e relativos comparados aos outros estados, para ser base de um desenvolvimento do setor farmacêutico regional mais dinâmico e inovativo. O estado, na maioria dos dados de ciência e tecnologia, também configura na segunda posição, atrás somente de SP - como acontece nos dados de atividades produtivas.

\section{4- Políticas de Apoio ao Setor Farmacêutico nos Estados}

Esta seção está dividida em duas subseções. Na primeira, são apresentadas as políticas estaduais de incentivo à inovação e ao desenvolvimento do setor farmacêutico nas suas leis e decretos e, na segunda, as formas de financiamento à inovação e ciência e tecnologia disponíveis em âmbito estadual para esse setor.

\section{1- As políticas estaduais de incentivo à inovação e ao setor farmacêutico}

Esta subseção analisa o panorama das ações governamentais do RJ para promoção da inovação e o compara com os demais estados estudados, SP, GO, MG, PE, para se ter um parâmetro de comparação, seguindo os moldes das seções acima. De modo geral, o arcabouço institucional de apoio à inovação tecnológica e desenvolvimento industrial, tanto no RJ quanto nos outros quatro estados de interesse, é centrado em uma lei estadual de inovação amparada por decretos reguladores e outros instrumentos de fomento, sumarizados na Tabela 5. As leis no 5.361/2008 (RJ), 16.922/2010 (GO), 17.348/2008 (MG), 13.690/2008 (PE) e 1.049/2008 (SP) têm em comum os objetivos de incentivar a interação empresa-ICT, particularmente, através de incentivos financeiros e da criação de núcleos de inovação tecnológica (NITs), parques tecnológicos e sistemas locais de inovação.

Exceto em SP, as leis estaduais de inovação preveem a criação de fundos para o financiamento de projetos de empresas inovadoras e de base tecnológica. Os Fundos de Apoio ao Desenvolvimento Tecnológico (Fatec-RJ) e de Incentivo à Inovação Tecnológica (FIIT-MG) são administrados pelas Fundações de Amparo à Pesquisa dos Estados do Rio de Janeiro (Faperj) e de Minas Gerais (Fapemig), respectivamente. Possibilitando, de certa forma, similaridades no apoio à pesquisa e ao desenvolvimento tecnológico no âmbito do RJ e do MG. A esse respeito, vale ressaltar as modalidades de cessão de valores por subvenção econômica, previstas na regulamentação do Fatec-RJ. De maneira complementar, a legislação do RJ permite ainda que a Faperj invista recursos em fundos de investimento, públicos ou privados, voltados ao 
financiamento de novas empresas inovadoras. SP e PE seguem o mesmo molde observado no RJ, porém, a permissão estende-se às autarquias e empresas públicas. Ademais, a lei do PE possibilita também a criação de um fundo de venture capital administrado pelo próprio estado ${ }^{11}$.

Ainda do ponto de vista de incentivo a empresas inovadoras, a lei de inovação do RJ prevê que produtos desenvolvidos nos seus termos tenham preferência nas compras de órgãos estaduais. Apenas PE segue um modelo semelhante, porém, não exige que o produto ou serviço seja inovador; observa apenas a necessidade de que a empresa fornecedora tenha investimentos em P\&D no estado.

Por outro lado, sob o aspecto do incentivo aos pesquisadores em ICTs, observa-se na legislação de todos os estados a intenção de garantir aos envolvidos a participação nas receitas geradas pela exploração de seus inventos. Nesse sentido, é interessante destacar a iniciativa da lei paulista, que inclui na partilha de benefícios os alunos participantes do desenvolvimento de produtos comercializados.

A estrutura estadual de suporte financeiro a iniciativas de inovação tecnológica é semelhante nos estados analisados. Nesse sentido, uma Fundação de Amparo à Pesquisa (FAP) atua no fomento à pesquisa e à interação empresa-ICT e uma agência de financiamento disponibiliza recursos às empresas, especialmente, àquelas com projetos inovadores. No RJ, a Faperj concede recursos a projetos de desenvolvimento científico e/ou tecnológico, garantindo suporte à comunidade científica presente nas ICTs e às empresas. Em outra frente, a Agência Estadual de Fomento (AgeRio) financia desde a implantação de infraestrutura laboratorial e de pesquisa até a prova de conceito, entre outras atividades. Além do suporte direto a empreendimentos, a AgeRio investe recursos no fundo privado BBI Financial, antigo Burril Brasil 1, o qual é destinado ao apoio a empresas no setor de Ciências da Vida, incluindo terapias e outras áreas afins.

Ademais, o RJ é o único a manter um segundo fundo de apoio ao desenvolvimento industrial e tecnológico, consolidando um ambiente favorável à inovação local. Além do Fatec, já mencionado, empresas instaladas no estado podem solicitar recursos do Fundo de Desenvolvimento Econômico e Social (Fundes), instituído pelo art. $6^{\circ}$ do Decreto-lei $n^{\circ}$ 08/75 e gerenciado pela Secretaria Estadual de Desenvolvimento Econômico, Energia, Indústria e Serviços (SEDEIS). Em 1998, o governo do estado instituiu o programa Rio Fármacos, através do Decreto $n^{\circ} 24.857$, regulamentando a utilização dos recursos do Fundes para subsidiar a expansão do setor farmacêutico local com linha de crédito de até $200 \%$ do valor do investimento fixo a ser realizado, com liberação em parcelas mensais durante os primeiros cinco anos de operação das novas instalações. O programa setorial prevê o desenvolvimento da indústria química fina de aplicações biotecnológicas no RJ.

Outro aspecto importante da estratégia conduzida pelo RJ a fim de estimular o setor farmacêutico é a concessão de incentivos fiscais, envolvendo, particularmente, o imposto sobre a circulação de mercadorias e serviços (ICMS). A esse respeito, o Decreto $n^{\circ}$ 37.209/05, que altera o Decreto $n^{\circ} 36.450 / 04$, prevê redução da carga tributária de $19 \%$ para $12 \%$ para operação de saída interna promovida entre contribuintes da cadeia farmacêutica e para $13 \%$ nas operações de saída para hospitais, clínicas e congêneres não contribuintes do ICMS. Ficam mantidos do Decreto $\mathrm{n}^{\circ} 36.450 / 04$, a redução de $4 \%$ de crédito presumido sobre 0 valor da nota fiscal nas saídas internas do industrial integrante da cadeia farmacêutica e o diferimento do imposto para casos de importação cujo desembaraço aduaneiro ocorra em portos ou aeroportos fluminenses, para aquisição interna de insumos e bens para o ativo fixo, ou ainda, para saída interna, promovida por fornecedor de mercadoria destinada à utilização como insumo na fabricação por estabelecimento industrial localizado no RJ integrante da

11 O referido fundo não foi encontrado durante o levantamento dos dados apresentados neste estudo. 
cadeia farmacêutica. É interessante observar que, dentre os estados pares, o RJ foi pioneiro em isentar de ICMS as operações internas envolvendo medicamentos de combate ao câncer (Convênio de ICMS no 162/94). Entretanto, a partir da assinatura do Convênio de ICMS nº $34 / 96$, os demais estados e o distrito federal puderam adotar o mesmo padrão.

Programas de incentivo ao desenvolvimento industrial são encontrados nos outros quatro estados investigados. Entretanto, importantes apelos setoriais voltados à indústria farmacêutica integram, em especial, as práticas adotadas nos estados de GO e PE. Atualmente, GO concentra esforços na coordenação das metas incorporadas nos programas de desenvolvimento de arranjos produtivos locais (APLs) e de incentivo à expansão das atividades industriais no estado. A indústria farmacêutica também integra o conjunto de indústrias privilegiadas pelo programa Produzir. Formalizado pela Lei $n^{\circ} 13.591 / 00$ e regulamentado pelo Decreto $n^{\circ} 5.265 / 00$, a plataforma oferece às empresas beneficiárias crédito de até $92 \%$ com base no valor devido em ICMS e desconto de até $50 \%$ sobre as cotas do mesmo imposto na forma de subvenção destinada a investimentos. É importante destacar também a isenção de ICMS para operações envolvendo medicamentos antiaids e insumos farmacêuticos ativos (IFA) relacionados.

De forma semelhante, PE concede tratamento tributário diferenciado à cadeia produtiva do setor farmacêutico. Através do Programa de Desenvolvimento de Pernambuco (PRODEPE), pautado na Lei $n^{\circ} 12.704 / 2004$, indústrias de diferentes setores, incluindo o farmacêutico, são beneficiadas pela concessão de crédito presumido de até $75 \%$ do saldo devedor de ICMS por 12 anos, podendo alcançar $95 \%$ caso a empresa se instale em regiões estratégicas definidas pelo governo estadual. Ademais, há ainda a previsão de crédito de compensação por frete, que pode alcançar $5 \%$ do valor das saídas interestaduais para localidades fora da região nordeste. Observa-se ainda, um esforço em promover o fortalecimento de APLs, tanto pelo direcionamento de recursos do PRODEPE quanto pelas medidas do Programa de Produção e Difusão de Inovações para a Competitividade de Arranjos Produtivos Locais do Estado de Pernambuco (PROAPL).

Em tempo, vale ressaltar o esforço empreendido por MG para promover, dentro de seu programa de APLs, o desenvolvimento e a integração de setores envolvidos com a biotecnologia. Paralelamente, o panorama do estado conta ainda com um expressivo incentivo à produção de medicamentos genéricos, cuja alíquota final de ICMS é reduzida de 18 para 4\%. Por fim, SP parece ter uma estrutura de apoio mais generalista e, sob alguns aspectos, menos atrativas para o setor farmacêutico. Apesar de contar com um programa de apoio a APLs e de garantir a isenção de ICMS a medicamentos antiaids e IFAs relacionados, ao lado de GO e MG, a carga tributária incidente sobre a indústria farmacêutica de SP é integral (18\%) e, por isso, é mais alta entre os cinco estados descritos. Todavia, o cenário fiscal desfavorável observado não impede que SP detenha a maior concentração de empresas do setor, como demonstrado por Paranhos e Hasenclever (2013). Essa situação leva a crer que os benefícios que as empresas encontram ao se instalarem no estado com a maior concentração industrial do país, grande disponibilidade de infraestrutura, assim como prestadores de serviços e fornecedores, são fatores de atração mais relevantes. 
Tabela 5: Tabela comparativa dos instrumentos de incentivo e suporte ao desenvolvimento industrial e à inovação tecnológica

\begin{tabular}{|c|c|c|c|c|c|}
\hline $\begin{array}{c}\text { Instrumentos } \\
\text { de Incentivo } \\
\text { à Inovação no } \\
\text { Estado }\end{array}$ & Rio de Janeiro & Goiás & Minas Gerais & Pernambuco & São Paulo \\
\hline $\begin{array}{l}\text { Leis Estaduais de } \\
\text { Inovação }\end{array}$ & $\begin{array}{l}\text { Lei n } 5.361 / 2008 \\
\quad \text { Prevê: } \\
\text { - Fomento à } \\
\text { interação E-ICT } \\
\text { utilizando recursos } \\
\text { da Faperj; } \\
\text { - Criação de NITs nas } \\
\text { ICTs do estado; } \\
\text { - Criação de parques } \\
\text { tecnológicos e } \\
\text { incubadoras nas } \\
\text { empresas; } \\
\text { - Apoio à criação } \\
\text { de sistemas de } \\
\text { inovação; } \\
\text { - Criação do Fatec; } \\
\text { - Participação de } \\
\text { pesquisadores nos } \\
\text { ganhos obtidos pela } \\
\text { exploração de seus } \\
\text { inventos; } \\
\text { - Preferência } \\
\text { a produtos } \\
\text { desenvolvidos nos } \\
\text { termos desta lei nas } \\
\text { compras de órgão } \\
\text { estatuais; } \\
\text { - Participação } \\
\text { da FAPERJ em } \\
\text { fundos públicos ou } \\
\text { privados voltados } \\
\text { ao financiamento } \\
\text { de novas empresas } \\
\text { inovadoras. }\end{array}$ & $\begin{array}{l}\text { Lei n 16.922/2010 } \\
\quad \text { Prevê: } \\
\text { - Incentivo à } \\
\text { interação E-ICT e } \\
\text { apoio financeiro a } \\
\text { empresas de base } \\
\text { tecnológica; } \\
\text { - Craição de NITS } \\
\text { nas ICTs do estado; } \\
\text { - Implantação } \\
\text { de sistemas } \\
\text { de inovação } \\
\text { administrados } \\
\text { pelas ICTs; } \\
\text { - Criação } \\
\text { de parques } \\
\text { tecnológicos e } \\
\text { incubadoras de } \\
\text { empresas; } \\
\text { - Participação de } \\
\text { pesquisadores nos } \\
\text { ganhos obtidos } \\
\text { pela exploração de } \\
\text { seus inventos. }\end{array}$ & $\begin{array}{l}\text { Lei n } 17.348 / 2008 \\
\quad \text { Prevê: } \\
\text { - Incentivo à } \\
\text { cooperação E-ICT; } \\
\text { - Criação de } \\
\text { NITs nas ICTs do } \\
\text { estado; } \\
\text { - Criação } \\
\text { de parques } \\
\text { tecnológicos e } \\
\text { incubadoras de } \\
\text { empresas; } \\
\text { - Implantação } \\
\text { de sistemas } \\
\text { de inovação } \\
\text { administrados } \\
\text { pelas ICTs; } \\
\text { - Criação do } \\
\text { Fundo Estadual } \\
\text { de Incentivo } \\
\text { à Inovação } \\
\text { Tecnológica - FIIT } \\
\text { - Participação de } \\
\text { pesquisadores nos } \\
\text { ganhos obtidos } \\
\text { pela exploração } \\
\text { de seus inventos. }\end{array}$ & $\begin{array}{l}\text { Lei n 13.690/2008: } \\
\quad \text { Prevê: } \\
\text { - Criação de NITs } \\
\text { nas ICTs do estado; } \\
\text { - Criação } \\
\text { de parques } \\
\text { tecnológicos e } \\
\text { incubadoras de } \\
\text { empresas; } \\
\text { - Sistema Estadual } \\
\text { de C, T, \&l; } \\
\text { - Criação de um } \\
\text { fundo Venture } \\
\text { Capital para } \\
\text { investimento } \\
\text { em empresas } \\
\text { inovadoras no EPE; } \\
\text { - Participação de } \\
\text { pesquisadores nos } \\
\text { ganhos obtidos } \\
\text { pela exploração de } \\
\text { seus inventos; } \\
\text { - Preferência, } \\
\text { nas compras do } \\
\text { poder público, } \\
\text { para a aquisição } \\
\text { de bens e serviços } \\
\text { de empresas que } \\
\text { invistam em P\&D } \\
\text { no estados; } \\
\text { - Participação } \\
\text { de empresas } \\
\text { e autarquias } \\
\text { estaduais em } \\
\text { fundos de } \\
\text { investimentos } \\
\text { destinados ao } \\
\text { financiamento } \\
\text { de inovação } \\
\text { tecnológica em } \\
\text { empresas. }\end{array}$ & $\begin{array}{l}\text { Lei n 1.049/2008: } \\
\quad \text { Prevê: } \\
\text { - Fomento à } \\
\text { interação E-ICT } \\
\text { utilizando recursos } \\
\text { da Fapesp; } \\
\text { - Criação do } \\
\text { Sistema Paulista } \\
\text { de Inovação } \\
\text { Tecnológica; } \\
\text { - Apoio financeiro } \\
\text { a empresas } \\
\text { inovadoras; } \\
\text { - Participação de } \\
\text { pesquisadores e } \\
\text { alunos nos ganhos } \\
\text { obtidos pela } \\
\text { exploração de seus } \\
\text { inventos; } \\
\text { - Participação } \\
\text { de empresas } \\
\text { e autarquias } \\
\text { estaduais em } \\
\text { fundos de } \\
\text { investimentos } \\
\text { destinados ao } \\
\text { financiamento } \\
\text { de inovação } \\
\text { tecnológica em } \\
\text { empresas. }\end{array}$ \\
\hline $\begin{array}{l}\text { Agências estaduais } \\
\text { de fomento }\end{array}$ & $\begin{array}{l}\text { - Faperj } \\
\text {-Agerio }\end{array}$ & $\begin{array}{c}\text {-Fapeg } \\
\text { - Goiás Industrial }\end{array}$ & $\begin{array}{c}\text { - Famig } \\
\text { - Banco de } \\
\text { Desenvolvimento } \\
\text { de Minas Gerais }\end{array}$ & $\begin{array}{l}\text { - Facepe } \\
\text { - AD Diper }\end{array}$ & $\begin{array}{c}\text { - Fapesp } \\
\text { - Agência } \\
\text { Desenvolve SP }\end{array}$ \\
\hline $\begin{array}{c}\text { Fundos } \\
\text { Estaduais para o } \\
\text { desenvolvimento } \\
\text { industrial/ } \\
\text { tecnológico }\end{array}$ & $\begin{array}{l}\text { - Fundes (SEDEIS) } \\
\text { - Fatec (SECT/Faperj) }\end{array}$ & $\begin{array}{c}\text { - Fundetec } \\
\text { (SECTEC) } \\
\text { - FUNPRODUZIR }\end{array}$ & $\begin{array}{l}\text { - FIIT (SECTES/ } \\
\text { Famig) }\end{array}$ & $\begin{array}{l}\text { Nenhum } \\
\text { fundo ativo foi } \\
\text { identificado }\end{array}$ & - Funcet (SDECTI) \\
\hline $\begin{array}{l}\text { Programas de } \\
\text { incentivo ao } \\
\text { desenvolvimento } \\
\text { industrial }\end{array}$ & $\begin{array}{c}\text { Dentre as iniciativas } \\
\text { setoriais, destaca- } \\
\text { se o Programa Rio } \\
\text { Fármacos. }\end{array}$ & $\begin{array}{l}\text { - Programa } \\
\text { Produzir } \\
\text { - Programa de } \\
\text { APLs }\end{array}$ & $\begin{array}{c}\text { Dentre as } \\
\text { iniciativas } \\
\text { setoriais, destaca- } \\
\text { se o suporte ao } \\
\text { desenvolvimento } \\
\text { do setor de } \\
\text { biotecnologia } \\
\text { dentro do } \\
\text { Programa de } \\
\text { apoio a APLs. }\end{array}$ & $\begin{array}{l}\text { - Prodepe } \\
\text { (Farmoquímica e } \\
\text { química fina) } \\
\text { - POAPL }\end{array}$ & $\begin{array}{c}\text { Dentre as } \\
\text { iniciativas, destaca- } \\
\text { se o Programa de } \\
\text { Fomento aos APLs. }\end{array}$ \\
\hline
\end{tabular}




\begin{tabular}{|c|c|c|c|c|c|}
\hline $\begin{array}{c}\text { Instrumentos } \\
\text { de Incentivo } \\
\text { à Inovação no } \\
\text { Estado }\end{array}$ & Rio de Janeiro & Goiás & Minas Gerais & Pernambuco & São Paulo \\
\hline $\begin{array}{c}\text { Incentivos } \\
\text { fiscais ao setor } \\
\text { farmacêutico }\end{array}$ & 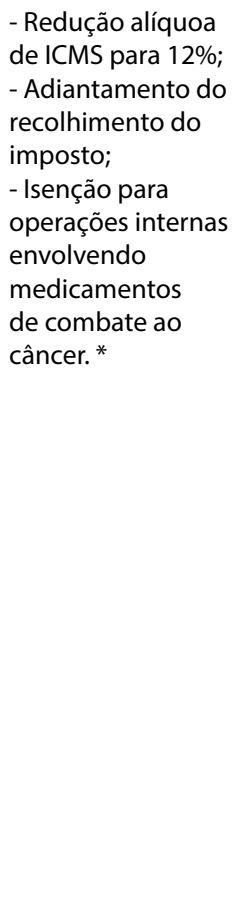 & $\begin{array}{l}\text { - Substituição } \\
\text { tributária em } \\
\text { operações } \\
\text { envolvendo } \\
\text { medicamentos, } \\
\text { soros e vacinas; } \\
\text { - Crédito } \\
\text { presumido do } \\
\text { ICMS variando } \\
\text { entre } 73 \% \text { e } 92 \% \\
\text { do saldo devedor } \\
\text { do imposto; } \\
\text { - Desconto de } \\
\text { até 50\% do saldo } \\
\text { devedor do ICMS } \\
\text { como subvenção } \\
\text { para investimento; } \\
\text { - Isenção de } \\
\text { ICMS para IFAs e } \\
\text { medicamentos } \\
\text { anti-AIDS; } \\
\text { - Isenção para } \\
\text { operações internas } \\
\text { envolvendo } \\
\text { medicamentos } \\
\text { de combate ao } \\
\text { câncer.** }\end{array}$ & $\begin{array}{l}\text { - Alíquoa final } \\
\text { de } 4 \% \text { para } \\
\text { medicamentos } \\
\text { genéricos; } \\
\text { - Isenção de } \\
\text { ICMS para IFAs e } \\
\text { medicamentos } \\
\text { anti-AIDS; } \\
\text { - Isenção para } \\
\text { operações } \\
\text { internas } \\
\text { envolvendo } \\
\text { medicamentos } \\
\text { de combate ao } \\
\text { câncer.** }\end{array}$ & $\begin{array}{l}\text { - Crédito } \\
\text { presumido do } \\
\text { ICMS variando } \\
\text { entre } 75 \% \text { e } 95 \% \\
\text { do saldo devedor } \\
\text { do imposto; } \\
\text { - Crédito de } \\
\text { compensação } \\
\text { por frete para } \\
\text { operações } \\
\text { interestaduais para } \\
\text { fora da região NE; } \\
\text { - Isenção para } \\
\text { operações internas } \\
\text { envolvendo } \\
\text { medicamentos } \\
\text { de combate ao } \\
\text { câncer.** }\end{array}$ & $\begin{array}{l}\text { - Isenção de } \\
\text { ICMS para IFAs e } \\
\text { medicamentos } \\
\text { anti-AIDS; } \\
\text { - Isenção para } \\
\text { operações internas } \\
\text { envolvendo } \\
\text { medicamentos } \\
\text { de combate ao } \\
\text { câncer.** }\end{array}$ \\
\hline
\end{tabular}

Fonte: Elaborado pelo GEI/IE/UFRJ com base nos sítios eletrônicos das secretarias estaduais de governo e nos textos das referidas leis e decretos.

Notas: (*): Convênio ICMS n 162/94: Autoriza o Estado do Rio de Janeiro a conceder isenção do ICMS nas operações internas com medicamentos destinados ao tratamento de câncer.

(**): Convênio ICMS n 34/96: Altera o Convênio ICMS n 162/94 permitindo aos estados e ao Distrito Federal a conceder isenção de ICMS para medicamentos quimioterápicos destinados ao tratamento de câncer.

\section{2- Papel das Fundações de Amparo à Pesquisa na construção do ambiente estadual de inovação}

No cenário de crescimento da importância de atividades de ciência, tecnologia e inovação, torna-se relevante, ao se discutir o papel do governo no apoio ao desenvolvimento do setor farmacêutico, analisar seus esforços no financiamento a projetos de interesse do setor. A literatura (MARTIN; SCOTT, 2000; MUNOS; CHIN, 2011; PARANHOS, 2012) mostra que, no âmbito do setor farmacêutico, o aporte de capital público contribui para a mitigação dos riscos associados principalmente às fases iniciais do desenvolvimento de novos medicamentos, favorecendo a execução de projetos inovadores em empresas do setor.

No Brasil, a atuação do governo federal no suporte aos diversos atores relevantes do setor farmacêutico no âmbito da inovação e da ciência e tecnologia é complementada na esfera estadual pela atuação das FAPs. O papel que era essencialmente de apoio à ciência e tecnologia passa a incorporar, gradualmente, o componente de fomento à interação empresa-ICT e à inovação. O financiamento público à pesquisa biomédica tem impactos positivos sobre a taxa de lançamento de novos medicamentos, constituindo importante componente da dinâmica de inovação da indústria farmacêutica (TOOLE, 2012).

No RJ, a atuação da Faperj é amparada por uma receita composta, principalmente, por transferências do estado correspondentes a $2 \%$ da arrecadação tributária líquida, além de outras 
fontes secundárias. Em termos absolutos, os valores seguem trajetória crescente, passando de R\$ 354 milhões dispendidos em 2010 para R\$ 398 milhões em 2013. Em comparação às FAPs dos demais estados analisados, o volume de recursos à disposição da Faperj é excedido apenas pela Fundação de Amparo à Pesquisa do Estado de São Paulo (Fapesp ${ }^{12}$ ). A regulamentação pertinente determina que a receita da agência seja composta por $1 \%$ da arrecadação ordinária de SP, que é naturalmente superior à do RJ. Entre transferências do estado e outras verbas, a Fapesp opera com receitas anuais superiores a R\$ 1 bilhão desde 2011 (FAPESP, 2015).

No período entre 2010 e 2013, foram identificadas 14 linhas de apoio coordenadas pela Faperj associadas ao suporte do desenvolvimento de conhecimento nas diversas áreas relevantes para o setor farmacêutico. Esse portfólio compreende 11 editais de suporte à ciência e à formação de recursos humanos em ICTs, e outros três que visam subsidiar o processo de inovação em empresas, com ou sem a participação de parceiros acadêmicos.

Considerando o intervalo temporal proposto, a Faperj realizou 25 editais distintos, através dos quais alocou pouco mais de $R \$ 220$ milhões. Desse montante, cerca de $R \$ 49$ milhões foram aplicados diretamente em empresas, ao passo que os quase $\mathrm{R} \$ 173$ milhões restantes foram destinados a projetos de ICTs. Nesse contexto, propostas apresentadas por empresas farmacêuticas corresponderam a $5,8 \%$ dos editais pertinentes (4), ao passo que projetos acadêmicos associados ao setor representaram 13,43\% (21) do universo de contemplações pelos editais de apoio ao desenvolvimento científico do RJ. Ao todo, os 25 editais observados selecionaram 1.650 projetos, dos quais, aproximadamente, $12,7 \%$ (210) estão relacionados ao setor farmacêutico, de maneira direta ou indireta.

A formação de mão de obra qualificada é um aspecto relevante para a construção da capacitação local em um determinado setor. Nesse sentido, a participação média de projetos de áreas de conhecimento pertinentes ao setor farmacêutico entre as propostas contempladas no edital de Treinamento e Capacitação Técnica foi superior a 10\% entre os anos de 2010 e 2013. Dentre os contextos avaliados, apenas a Faperj parece dedicar recursos exclusivos para fomentar a qualificação de pessoal técnico. Outro ponto de pioneirismo da Agência é a abertura de uma linha de apoio à realização de ensaios clínicos em instituições sediadas no RJ, iniciado em 2013. A estruturação de instituições de saúde, ensino e pesquisa para viabilizar a realização de testes clínicos é imprescindível à dinâmica de inovação na indústria farmacêutica e pode representar um diferencial ao ambiente do RJ.

Algumas linhas de fomento são comuns entre as FAPs analisadas, especialmente aquelas realizadas em parceria com órgãos do governo federal, caso do "Tecnova", que direciona recursos repassados pela Finep às empresas inovadoras via subvenção econômica. De maneira similar, os editais de "Pesquisa para o SUS" fazem uma ponte entre provisões garantidas pelo Ministério da Saúde e ICTs locais. Entre as linhas sustentadas com recursos próprios das FAPs, o apoio à criação e/ou manutenção de NITs está presente no portfólio da Faperj, Fundação de Amparo à Pesquisa do Estado de Goiás (Fapeg) e Fapemig. Por outro lado, o suporte a incubadoras de empresas de base tecnológica integra a agenda regular da Faperj e da Fapemig.

No âmbito da Fapesp, o apoio a empresas se dá através de quatro linhas de editais, envolvendo ou não a interação com ICTs. Dos projetos correntes, aproximadamente $4,8 \%$ estão associados à indústria farmacêutica. Do ponto de vista do apoio à academia, a proporção de projetos pertinentes ao setor farmacêutico alcança os $6 \%$, ao menos no que diz respeito à principal linha de fomento coordenada pela Fapesp para suporte à pesquisa acadêmica. Em termos absolutos, o número de projetos relacionados ao setor farmacêutico conduzidos com apoio da Fapesp

12 Segundo as constituições dos estados de Pernambuco e Goiás, a transferência de recursos obrigatórios às entidades estaduais de apoio à pesquisa corresponderá a 0,5\% da receita líquida de impostos. Em MG, a constituição estadual determina a disponibilização de $1 \%$ da receita orçamentária corrente ordinária para formação de recursos da Fapemig. 
parece ser maior do que o volume correspondente no contexto da Faperj, apesar do quadro se inverter quando a comparação é feita em números relativos.

O suporte à inovação realizado pela Fapesp está dividido em quatro linhas que garantem apoio às empresas inovadoras e à interação empresa-ICT. Dentre estas, o Consórcios Setoriais para Inovação Tecnológica (ConSITec) parece ter sido desativado, visto que não foram encontrados projetos em andamento sob a tutela desse programa. Por outro lado, há de se destacarem as parcerias entre grandes farmacêuticas multinacionais e ICTs intermediadas pela Fapesp. São ao menos quatro projetos da GSK em conjunto com diferentes instituições de pesquisa do estado. A Agência oferece ainda uma categoria de fomento exclusiva para o apoio à proteção intelectual por parte das ICTs do estado.

Na relação das demais agências de fomento com o ambiente de inovação local, a Fapemig se sobressai por dispor de editais organizados em conjunto com empresas privadas de MG, mas, até o momento, nenhuma do setor farmacêutico. A agência tem especial cuidado com o incentivo ao desenvolvimento da capacitação local em biotecnologia. Entretanto, a maior parcela dos projetos contemplados ainda envolve aplicações não pertinentes à indústria farmacêutica. $\mathrm{A}$ Fapeg, em GO, e a Fundação de Amparo à Pesquisa do Estado de Pernambuco (Facepe) ainda têm atuações mais restritas, proporcionais aos recursos com os quais operam. Entretanto, no que diz respeito ao apoio à ICTs, é válido destacar a parceria estabelecida entre a Facepe e o Centro de Pesquisa Aggeu Magalhães (Fiocruz - PE). Sob o ponto de vista do incentivo direto à inovação em empresas, Fapeg e Facepe parecem contar apenas com o edital Tecnova, iniciado em 2013 e mantido em 2014.

A atuação da Faperj no sistema de inovação fluminense vem evoluindo de maneira sustentada. Tal progresso se reflete no volume crescente de recursos disponibilizados por ano e a criação de novos editais, especialmente contemplando as ciências da vida. O percentual de projetos associados ao setor farmacêutico frente ao total de estudos apoiados pela Faperj é relativamente baixo. Porém, parece semelhante ao observado no contexto da Fapesp e bastante superior às demais FAPs. Ao menos em termos de estudos em execução e de formação de recursos humanos especializados, os dados apresentados permitem argumentar que, em comparação a estados pares, o panorama do RJ parece favorável ao estabelecimento e manutenção da indústria farmacêutica no estado.

\section{5- Discussão dos Dados e Conclusão}

O setor farmacêutico nacional vem sendo alvo de políticas de apoio ao seu desenvolvimento produtivo e inovativo desde o início dos anos 2000, e os resultados demonstram que tais políticas têm levado o setor a estágios superiores de desenvolvimento, conforme indicado por Ferraz, De Paula e Kupfer (2013). O setor farmacêutico nacional apresenta um grande crescimento na produção física e no emprego no setor, acompanhada, porém, por uma redução no número de estabelecimentos. No entanto, as políticas nacionais são abrangentes para todas as empresas do setor no país, não tendo qualquer preocupação com as diferenças de concentração regional do setor. Tradicionalmente, há no Brasil uma concentração espacial nos estados de SP e RJ, principais estados da federação, que apresentam maior riqueza e concentração da produção e de ciência e tecnologia. Por esse motivo, ações e políticas estaduais são importantes no sentido de mudar a estrutura e configuração do setor em âmbito nacional.

De acordo com os dados apresentados neste artigo, as políticas industriais e tecnológicas estaduais estão tendo sucesso no sentido de modificar a participação de alguns estados na configuração do setor farmacêutico. Ademais, a ausência de políticas específicas em outros estados, inicialmente 
relevantes para o setor, está fazendo com que estes percam sua importância no cenário nacional. Tal resultado reforça a importância das ações sistêmicas com enfoque regional para promoção do desenvolvimento produtivo e inovativo, conforme defendido por Cooke (1998).

A análise dos dados mostra, particularmente, uma perda de importância do estado previamente relevante em termos produtivos - o RJ, que tem perda relativa e absoluta nos estabelecimentos, emprego e produção do setor - e um crescimento da participação do setor em outros - como GO, que chega à terceira posição em termos de concentração de empresas e à segunda posição em termos de emprego no setor, superando o RJ. Interessante notar, porém, que a liderança de SP é mantida em termos dos estabelecimentos e emprego, além do forte crescimento da produção física.

Por outro lado, em termos de capacitação científica e tecnológica para o setor, SP e RJ, principais polos do país, permanecem como os estados mais relevantes. O RJ só perde a segunda colocação para MG no número de cursos de graduação ligados diretamente ao setor farmacêutico. Porém, na pós-graduação e na pesquisa, SP lidera seguido do RJ.

Em termos de políticas para o desenvolvimento do setor farmacêutico no estado, nota-se que todos os estados estudados têm algum tipo de ação nesse sentido, além de ações para a geração de inovação e promulgação de Leis de Inovação em alinhamento ao padrão nacional. Percebe-se a criação de programas de apoio ao desenvolvimento de parceria entre empresas e ICTs, assim como de subvenção econômica a empresas para projetos de inovação. Ressalta-se, porém, o forte uso de incentivos fiscais, particularmente, em GO. No entanto, estes são direcionados, principalmente, a atividades produtivas, e não inovativas, como a literatura sugere para o melhor estímulo ao desenvolvimento dos SRI (COOKE, 1998; FERRAZ; DE PAULA; KUPFER, 2013).

Percebe-se que em SP, diferentemente, do RJ, as ações e políticas no sentido de desenvolvimento do setor farmacêutico e apoio às suas atividades inovativas vêm sendo realizadas de forma mais consistente e contínua há mais tempo, permitindo a manutenção dessa liderança. Com intuito de reverter essa situação, foi criado o Grupo Executivo do Complexo Industrial em Ciências da Vida do Rio de Janeiro (GECIV-RJ) com a finalidade de elaborar e desenvolver as diretrizes das políticas estaduais de fortalecimento do complexo produtivo e de inovação em ciências da vida (Decreto estadual no 43.315/2011). A criação do GECIV-RJ apresenta grande potencial nesse sentido, pois engloba diversos atores ligados ao setor no estado e vem buscado ampliar a articulação entre eles. Além disso, vem realizando estudos para um melhor mapeamento das potencialidades do RJ para o desenvolvimento do setor farmacêutico.

O estudo comparativo das políticas e programas estaduais permite identificar alguns gargalos a serem superados no RJ: a) a necessidade de revisão da carga tributária que incide sobre a produção e a distribuição do setor farmacêutico; b) a criação de incentivos fiscais a atividades de P\&D; c) a criação de políticas industriais e de inovação na esfera local, especialmente a fim de fortalecer a infraestrutura tecnológica capaz de promover uma melhor interação empresa-ICT; d) a melhor estruturação e organização em prol do empreendedorismo. 


\section{Referências Bibliográficas}

ASHEIM, B.; GERTLER, M. The geography of innovation: regional innovation system. In: FAGERBERG, J.; MOWERY, D.; NELSON, R. The Oxford handbook of innovation. New York: Oxford University Press, 2005, p. 291-317.

BERMUDEZ, J.; EPSZTEJN, R.; OLIVEIRA, M. A.; HASENCLEVER, L. O Acordo TRIPS da OMC e a Proteção Patentária no Brasil: mudanças recentes e implicações para a produção local e o acesso aos medicamentos. Rio de Janeiro: Fiocruz/ENSP, 2000.

BRESCHI, S.; MALERBA, F. Sectorial innovation systems: technological regimes, schumpeterian dynamics, and spacial boundaries. In: EDQUIST, C. (Ed.). Systems of innovations: technologies, institutions and organizations, London: Printer, 1997, p. 130-155.

BRITTO, J. N. P.; BITTENCOURT, P. F.; CRUZ, W.M.S. Interação infraestrutura de ciência e tecnologia (C\&T) e setor produtivo no estado do Rio de Janeiro. In: SUZIGAN, W; MOTTA E ALBUQUERQUE, E.; CARIO, S. (Org.). Em Busca da Inovação: interação universidade-empresa no Brasil. Belo Horizonte: Autêntica Editora, 2011.

BUSS, P.; CARVALHEIRO, J.; CASAS, C. (Org.). Medicamentos no Brasil: inovação e acesso. Rio de Janeiro: Editora Fiocruz, 2008.

CAPES - Coordenação de Aperfeiçoamento de Pessoal de Nível Superior. Estatísticas: Sistema Geocapes 2013. Disponível em: <www.capes.gov.br>. Acesso em: 10 fev. 2015.

CNPq - Conselho Nacional de Desenvolvimento Científico e Tecnológico. Plano Tabular 2010. Disponível em: <www.cnpq.br>. Acesso em: 11 jun. 2015.

COOKE, P. Introduction: origins of the concept. In: BARACZYK, H.; COOKE, P.; HEIDENREICH, R. (Eds). Regional Innovation Systems: the role of governances in a globalized world, London: UCL Press, 1998.

COOKE,P.;URANGA, M.;ETXEBARRIA, G. Regional innovation systems:Institutional and organisational dimensions. Research Policy, v. 26, n. 4-5, p. 475-491, 1997.

FAPESP - Fundação de Amparo à Pesquisa do Estado de São Paulo. Evolução das Receitas. Disponível em: <www.fapesp.br/9250>. Acesso em: 03 set. 2015.

FERRAZ, J.C.; DE PAULA, G.; KUPFER, D.; Política industrial. In: KUPFER, D.; HASENCLEVER, L. (Orgs). Economia Industrial: fundamentos teóricos e práticas no Brasil, Rio de Janeiro: Ed. Campus, 2013.

FREEMAN, C. The 'National System of Innovation' in historical perspective. Cambridge Journal of Economics, v. 19, p. 5-24, 1995.

GOMES, E. Clusters e biotecnologia para a superação da imitação: estudo de caso da indústria farmacêutica brasileira. 2004. 376f. Tese de Doutorado - Rio de Janeiro: IE/UFRJ, 2004. (Tese de Doutorado em Políticas Públicas, Estratégias e Desenvolvimento)

HASENCLEVER, L. (Coord.). Interação entre instituições de ciência e tecnologia e empresas no sistema farmacêutico de inovação brasileiro: lições para o desenvolvimento do setor no Estado do Rio de Janeiro. Relatório de Pesquisa. Rio de Janeiro: Faperj/UFRJ/Instituto de Economia, 2012.

HASENCLEVER, L.; PARANHOS, J.; TORRES, R. Desempenho econômico do Rio de Janeiro: trajetórias passadas e perspectivas futuras. DADOS-Revista de Ciências Sociais, Rio de Janeiro, v. 55, n. 3, p. 681-711, 2012.

IBGE - Instituto Brasileiro de Geografia e Estatística. Pesquisa Industrial Mensal - Produção Física, 1996-2012. Rio de Janeiro: IBGE, 2013. 
KLEVORICK, A. et al. On the sources and significance of inter-industry differences in technological opportunities. Research Policy, v. 24, p. 185-205, 1995.

LESSA, C. O Rio de todos os Brasis: 3. ed. Rio de Janeiro: Ed. Record, p. 345-412, 2000.

LUNDVALL, B.-Å. et al. National systems of production, innovation and competence building. Research Policy, v. 31, p. 213-231, 2002.

MALERBA, F. Sectoral systems: how and why innovation differs across sectors. In: FAGERBERG, J.; MOWERY, D. C. (Ed.). The Oxford handbook of innovation. New York: Oxford Universtiy Press, p. 380-406, 2005.

MANSFIELD, E. Academic research and industrial innovation: an update of empirical findings. Research Policy, v. 26, p. 773-776, 1998.

MARTIN, S.; SCOTT, J. The nature of innovation market failure and the design of public support for private innovation. Research Policy, v. 29, n. 4-5, p. 437-447, 2000.

MCKELVEY, M.; ORSENIGO, L. Pharmaceutical as a sectoral innovation system. Research Report of ESSY Project and Epris Project, Nov. 2001, (mimeo). Disponível em: www.druid.dk. Acesso em: 19 set. 2007.

MEC - Ministério da Educação. Sistema e-MEC 2015. Disponível em: <www.mec.gov.br>. Acesso em: 10 ago. 2015.

MTE - Ministério do Trabalho e Emprego. Relação Anual de Informações Sociais, 1995-2013. Disponível em: <www.mte.gov.br>. Acesso em: 06 abr. 2015.

MUNOS, B.; CHIN, W. How to Revive Breakthrough Innovation in the Pharmaceutical Industry. Science Translational Medicine, v. 3, n. 89 cm16, p. 1-3, 2011.

PALMEIRA FILHO, P. Catch-up da indústria farmacêutica nacional e financiamento à inovação: o caso da atuação do BNDES através do Profarma. 2013. 242f. Tese de Doutorado - Rio de Janeiro: EQ/UFRJ, 2013.

PARANHOS, J. Interação entre empresas e instituições de ciência e tecnologia: o caso do sistema farmacêutico de inovação brasileiro. Rio de Janeiro: Eduerj, 2012.

RADAELLI, V. Trajetórias inovativas do setor farmacêutico no Brasil: tendências recentes e desafios futuros. 2012. 288f. Tese de Doutorado - Campinas: DPCT/Unicamp, 2012. (Tese de Doutorado em Política Científica e Tecnológica)

SELAN, B.; KANNEBLEY JÚNIOR, S.; PORTO, G. S. Relatório setorial sobre inovação tecnológica na indústria farmacêutica brasileira: uma análise a partir dos indicadores de inovação. Ribeirão Preto: Fipase, 2007.

TOOLE, A. The impact of public basic research on industrial innovation: Evidence from the pharmaceutical industry. Research Policy, v. 41, n. 1, p. 1-12, 2012. 